\title{
Empirical Study on the Relationship between R\&D Expenditure and GDP in Guangdong Province
}

\author{
Jinghua $\mathrm{Hu}$ \\ School of Applied Mathematics of Beijing Normal \\ University Zhuhai Campus \\ BNUZ \\ Zhuhai, China \\ 13726287953@163.com
}

\author{
Yue Lan* \\ School of Applied Mathematics of Beijing Normal \\ University Zhuhai Campus \\ BNUZ \\ Zhuhai, China \\ 465483066@qq.com
}

\begin{abstract}
R\&D activities are highly valued by countries around the world for their creativity and novelty. After the introduction of the concept of $R \& D$ in the 1980 s to China, Chinese scholars have never stopped the research on the effect of R\&D expenditure on economic growth. This paper selects the R\&D expenditures and GDP data of Guangdong Province from 2000 to 2013, studies the relationship between R\&D expenditure and GDP with the help of the impulse response function in VAR model, and draws a conclusion that the $R \& D$ expenditure has a positive effect on GDP growth and GDP growth has a "lagging effect" on R\&D expenditure. Finally, by analyzing the relationship between the above two, this paper also puts forward some suggestions for the government and companies with respect to their R\&D expenditure.
\end{abstract}

Keywords-R\&D; Guangdong Province; VAR model; Impulse response function

\section{INTRODUCTION}

R\&D activities reflect a country's scientific and technological strength and core competitiveness, and are highly valued by countries around the world for the creativity and novelty.

Between 2000 and 2013, Guangdong's R\&D expenditure increased from 10.712 billion yuan in 2000 to 144.345 billion yuan in 2013 with an increase of $1247.51 \%$. The national increase rate of $\mathrm{R} \& \mathrm{D}$ expenditure during the 14 years was $93.57 \%$. The increase rate of Guangdong is far above the national growth rate. The R\&D expenditure per capita of R\&D personnel in Guangdong Province in 2013 was 287,700 yuan with an increase of $90.53 \%$ compared with 151,000 yuan in 2000. The proportion of R\&D expenditure as a percentage of GDP increased from $0.9973 \%$ in 2000 to $2.3105 \%$ in 2013 . As a highly developed economic region, Guangdong Province also ranks among the top $\mathrm{R} \& \mathrm{D}$ expenditure of China.

Although Guangdong Province has made great progress in R\&D activities, there are still regional investment imbalances, low input intensity, low overall efficiency and other problems.

\section{LITERATURE REVIEW}

In neoclassical economic theory, economists such as C.W.Cobb and P.H.Douglas have linked science and technology to economic growth. Followed by Paul.Romer, scholars continue to internalize technological innovation and $\mathrm{R} \& \mathrm{D}$ expenditure in the new economic growth theory. Under the new economic situation, scholars both at home and abroad have conducted in-depth studies on the economic benefits of R\&D from all aspects and perspectives, and have continuously improved and enriched the contents of R\&D. China also introduced the concept of R\&D in the 1980s and conducted a national R\&D inventory in 2000 and 2009.

Hong Cancheng (2015) established a fixed-effect variable coefficient model and analyzed that R\&D expenditure had a positive impact on the economic growth of the cities of Guangdong and Shandong provinces from 2007 to 2013[1]. Chen Xinwei and Yao Zuowen (2011) used ADL model to conduct empirical research on R\&D expenditure and total GDP data of Anhui Province from 1994 to 2008 and concluded that R\&D expenditure in Anhui Province made a significant contribution to economic growth[2].

Xu Shuyi, Tian Baoqin, Zhu Fuqiang (2011) made use of the panel data of 21 prefecture-level cities in Guangdong Province to conduct an empirical study on the relationship between R\&D and productivity in Guangdong Province: they considered that there was a bias in $R \& D$ expenditure which did not actually invest in those areas that really promote productivity[3]. Yan Chengliang and Gong Liutang (2014) built an R\&D-driven endogenous growth model to study the contribution of China's R\&D to economic growth, and found that $R \& D$ contribution to economic growth was relatively small due to the low proportion of $R \& D$ expenditure to GDP[4].

Zhang Jinshui (2007) concluded that during the "10th FiveYear Plan" period, Guangdong Province's R\&D activities were mainly based on enterprises and experimental development, the Pearl River Delta was the main area and R\&D/GDP growth was slow[5].

Zhu Mingming (2013) used the impulse response function of VAR model to study R\&D expenditure and regional GDP of 
Fujian Province from 1987 to 2010 and concluded that R\&D expenditure contributed to the promotion of GDP and R\&D expenditure had "lagging effect" and "hysteresis effect"[6]. Qi Siyun (2012) also found that the impact of R\&D expenditure on GDP has a lagging effect. The actual R\&D expenditure in the first two periods will affect the actual GDP of the current period [7]. Liu Lu and Guo Bing (2012) measured the lagging effect from R\&D and GDP data of Shanghai from 1999 to 2010 which indicated that R\&D expenditure in Shanghai had a significant driving effect on economic growth, but it showed rapid downward trend with the extension of the lagging years [8].

Song Wenfei, Wang Jue and Han Xianfeng (2011) used three-phase DEA method to measure regional R\&D efficiency in China and discovered that the overall efficiency of R\&D in China was not high and R\&D efficiency still has room for improvement [9].

\section{EMPIRICAL ANALYSIS}

\section{A. Data sources and variables}

This paper's data on R\&D expenditure of Guangdong Province from 2000 to 2013 is from the Guangdong High-tech Industry Network. GDP data of Guangdong Province is from Guangdong Statistical Yearbook[10]. Taking R\&D expenditure as independent variables and GDP as the dependent variables.

\section{B. Model establishment}

- A co-integration analysis of R\&D expenditure and GDP is used to find the long-term equilibrium relationship between the two. Then VAR model is taken to estimate R\&D expenditure and GDP; then Granger test is used to explore the causal relationship between $R \& D$ expenditure and GDP; finally impulse responses is chosen to analyze the impact of $R \& D$ expenditure on GDP and assess R\&D expenditure dynamic relationship with GDP.

- Stability test

In order to test whether there is a cointegration relationship between R\&D expenditure and GDP, we must first test the stability of the data, otherwise false regression may occur, resulting in invalid analysis results. ADF test is used to ensure the validity of the results. Since logarithmic transformation of data does not change the cointegration relationship of the data itself. In order to eliminate the heteroscedasticity of time sequences, the logarithm of data is taken in order to examine the sensitivity of R\&D expenditure to GDP, which is shown in Table 1.

TABLE I STABILITY TEST

\begin{tabular}{ccccc}
\hline \hline Variables & ADF value & $1 \%$ level & P value & Conclusion \\
\hline \hline LNR\&D & 14.900 & -2.755 & 0.999 & Unstable \\
DLNR\&D & -0.329 & -2.792 & 0.554 & Unstable \\
DDLNR\&D & -4.943 & -2.792 & 0.000 & Stable \\
LNGDP & 1.497 & -2.772 & 0.957 & Unstable \\
DLNGDP & -0.582 & -2.812 & 0.440 & Unstable \\
DDLNGDP & -4.280 & -2.817 & 0.000 & Stable \\
\hline \hline
\end{tabular}

Note: D is first-order differential and DD is secondorder differential.

It can be seen from Table 1 that both $R \& D$ expenditure and GDP are non-stationary, while the second-order differentials are all stable at $1 \%$ level, so both variables are second-order monotonic sequences.

- Cointegration test

According to the unit root test results, both $\mathrm{R} \& \mathrm{D}$ expenditure and GDP are second-order differentials and there is a cointegration relationship between the two. This paper uses Johansen test to perform cointegration test on R\&D expenditure (LNR\&D) and GDP (LNGDP) sequences. The results are shown in Table 2.

TABLE II JOHANSEN COINTEGRATION TEST

\begin{tabular}{|c|c|c|c|}
\hline $\begin{array}{l}\text { Hypothesized } \\
\text { No.of CE(s) }\end{array}$ & Eigenvalue & $\begin{array}{c}\text { Trace } \\
\text { Statistic }\end{array}$ & $\begin{array}{l}5 \% \\
\quad \text { Critical Value }\end{array}$ \\
\hline None & 0.951 & 38.204 & 0.000 \\
\hline At most 1 & 0.369 & 5.062 & 0.024 \\
\hline \multicolumn{4}{|c|}{ Trace test indicates 2 cointegrating eqn(s) at the 0.05 level } \\
\hline
\end{tabular}
hypothesis that there are two co-integration relations between R\&D expenditure and GDP. After establishing the standard, the cointegration equation is as follows:
From equation (1), it can be seen that there is a longterm stable and balanced relationship between R\&D expenditures, indicating that the long-term elasticity coefficient of R\&D expenditure on GDP is 0.6368 . That 
is, for each $\mathrm{R} \& \mathrm{D}$ expenditure increase of one percentage, GDP will increase by $0.6368 \%$, which shows that R\&D expenditure during 2000-2013 have contributed to GDP growth.
According to AIC, SC, LR and other standards to determine the minimum determined $\mathrm{R} \& \mathrm{D}$ expenditure and the lagging orders of variables of GDP in model, the results are shown in Table 3.

- VAR model establishment analysis

TABLE III DETERMINATION OF LAGGING ORDERS

\begin{tabular}{cccc}
\hline \hline Lagging period & LR & AIC & SC \\
\hline \hline 0 & NA & -1.1152 & -1.0547 \\
1 & 51.7382 & -7.7064 & -7.5248 \\
2 & 0.6245 & -7.0313 & -6.7287 \\
3 & 14.9265 & -11.2068 & -10.7832 \\
4 & $42.7007 *$ & $-53.1075^{*}$ & $-52.5628^{*}$ \\
\hline \hline
\end{tabular}

From Table 3, it can be seen that the optimal lagging order of VAR model is 4 , that is, R\&D expenditure and GDP constitute VAR(4) model.

$$
\begin{aligned}
& L N G D P_{t}=-0.3105 L N R \& D_{t-1}+1.1265 L N G D P_{t-1}+1.1787 L N R \& D_{t-2}+0.0241 L N G D P_{t-2}-0.5804 \\
& (0.3687)
\end{aligned}
$$

$$
R^{2}=0.9964 \quad F-\text { statistic }=479.743 \quad \text { AIC }=-3.6623
$$

From the above formula, it can be seen that GDP is affected by the previous period of $R \& D$ expenditure and GDP. It shows that when R\&D expenditure increases by $1 \%$ in the previous period, GDP in the current period drops by $0.3105 \%$; when GDP increases by $1 \%$ in the previous period, GDP in the current period increases by $1.1265 \%$. The meanings of the first two periods is similar.
Co-integration relationship and VAR model are used to prove that there is a long-term equilibrium relationship between R\&D expenditure and GDP. In order to further explore whether R\&D expenditure affects GDP or GDP affects $R \& D$ expenditure, it is necessary to examine them again. The interaction of all variables in VAR model is used and the lagging order is chosen to be 2 and the results are given in Table 4.

- Granger causal test

TABLE IV

GRANGER CAUSAL TEST

\begin{tabular}{ccccc}
\hline \hline lags & Null Hypothesis & F-Statistic & Prob. & Conclusion \\
\hline \hline \multirow{2}{*}{1} & LNGDP does not Granger Cause LNR\&D & 9.2810 & 0.0123 & Reject \\
& LNR\&D does not Granger Cause LNGDP & 1.1836 & 0.2053 & Accept \\
\hline \multirow{2}{*}{2} & LNGDP does not Granger Cause LNR\&D & 5.7328 & 0.0335 & Reject \\
& LNR\&D does not Granger Cause LNGDP & 0.4389 & 0.6613 & Accept
\end{tabular}

Granger causal test is performed on the data. At 5\% level, both the lagging orders 1 and 2 reject null hypothesis of "LNGDP does not Granger Cause LNR\&D" and accept the null hypothesis of "LNR\&D does not Granger Cause LNGDP", which shows that China's R\&D expenditure is not a Granger cause of GDP growth and GDP is the Granger cause of R\&D expenditure.
- Impulse response in VAR model

It can be obtained after modeling:

$\left(\begin{array}{l}L N G D P \\ L N R \& D\end{array}\right)=\left(\begin{array}{c}1.1265-0.3105 \\ 0.30940 .7385\end{array}\right)\left(\begin{array}{l}L N G D P_{t-1} \\ L N R \& D_{t-1}\end{array}\right)+\left(\begin{array}{l}-0.5803 \\ -2.8829\end{array}\right)$

The values of AIC and SC are estimated by VAR model to be -3.3623 and -3.1603 respectively. Both of 
these values are small, which shows that the overall effect of the model is better. The impulse of the model is impacted by the error term. The result is shown in Figure 1 in Figure 2.

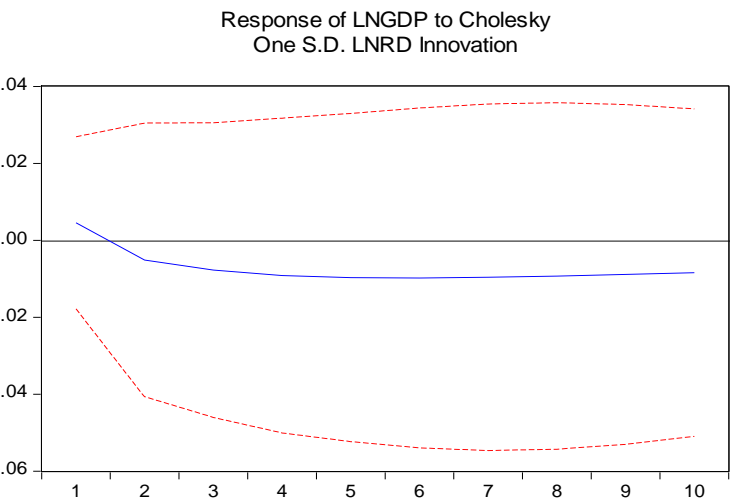

Fig. 1 Impulse Response of GDP to R\&D Expenditure Response of LNRD to Cholesky One S.D. LNGDP Innovation

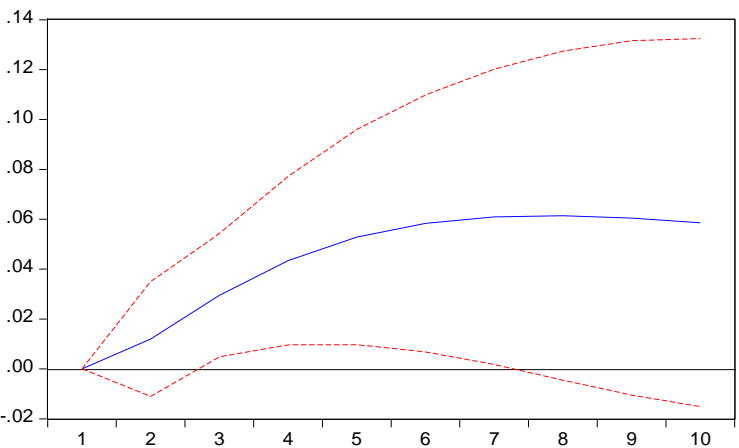

Fig. 2 Impulse Response of R\&D Expenditure to GDP

From Figure 1, it can be concluded that after being hit by a standard, R\&D expenditure of the first three periods begin to fall to low values and then remain stable, indicating that GDP growth is faster than R\&D expenditure and does not promote the growth of R\&D expenditure in short term. Over time, it may increase the decline in $R \& D$ expenditure.

From Figure 2, it can be concluded that after being hit by a standard, GDP of the first six periods show an upward trend and then remain stable, indicating that $R \& D$ expenditure has a positive effect on GDP. In a long term, the impact of R\&D expenditure on GDP will tend to be stable.

In summary, China's R\&D expenditure is less affected by GDP, and the impact is stable after 2 years, and there may be an upward trend; R\&D expenditure also contributes to GDP and increases from the first year. After 6 years, it tends to be stable and has a long-term effect.

\section{CONCLUSION AND SUGGESTIONS}

Based on the above empirical analysis, we can conclude that $R \& D$ expenditure has a positive effect on the growth of GDP. The long-term elasticity coefficient of R\&D expenditure on GDP is 0.6368 , that is, for each $R \& D$ expenditure increase of one percentage, GDP will increase by $0.6368 \%$, but there is "lagging effect" in R\&D expenditure. R\&D expenditure of the first two periods will affect current GDP. How to maximize the impact of R\&D expenditure on GDP in Guangdong Province and use $R \& D$ to solve long-standing imbalance in regional development of Guangdong Province and increase R\&D expenditure, and how to increase the efficiency of $R \& D$ expenditure conversion are the focuses which Guangdong Provincial Government need to consider in the future.

\section{A. Increase $R \& D$ expenditure to narrow regional disparities}

Empirical analysis shows that R\&D expenditure has a positive effect on GDP growth, while insufficient R\&D expenditure is Eastern and Western and Northern Guangdong are bound to restrain GDP growth in their regions. Because each region has its own different industries, in the future, Guangdong Province should increase its policy guidance on the eastern and western regions, increase the investment in $R \& D$ expenditure of eastern, western and northern regions of Guangdong, and give appropriate preferential policies and financial allocations. By increasing R\&D expenditure and driving GDP growth in the eastern, western and the northern regions, the long-standing pattern of economic development in Guangdong Province will be narrowed and a regional layout with different industrial structures and industrial characteristics will be built. At the same time, with the Pearl River Delta region as the core, a high-tech industrial group with international competitiveness will be established, a high-tech industrial park will be invested and established with the purpose of creating high-tech products and building the Pearl River Delta region into a high-tech industrial base with global competitiveness. At the same time, increase $\mathrm{R} \& \mathrm{D}$ expenditure in the eastern, western and the northern regions of Guangdong Province, increase the scientific and technological content and market competitiveness of the regional support industries, vigorously foster regional R\&D companies, encourage innovation and creativity, increase the participation of Guangdong Province in science and technology work and promote the provincial economy's common prosperity.

\section{B. Appropriately increase the intensity of $R \& D$ expenditure}

Compared with other developed cities of China, R\&D expenditure in Guangdong Province are second only to that of Jiangsu Province. However, the $R \& D$ expenditure in Guangdong Province is far less than that of Beijing, Shanghai and other places. In the future, Guangdong Province should pay more attention to increase the intensity of $R \& D$ expenditure. In terms of the economy of Guangdong Province in the current period, increasing $R \& D$ expenditure will inevitably result in a reduction in other aspects of investment. Therefore, we advocate a modest increase in $\mathrm{R} \& \mathrm{D}$ expenditure, and appropriately increase $R \& D$ expenditure and the intensity 
of $R \& D$ expenditure without undermining the existing economic structure and stability of Guangdong Province.

\section{Improve the efficiency of $R \& D$ expenditure conversion}

From the empirical analysis, we analyzed that R\&D expenditure in Guangdong Province have a positive effect on GDP. However, for every one percentage point increase in $\mathrm{R} \& \mathrm{D}$ expenditure, the GDP in the current period only increases by $0.6368 \%$, which indicates that R\&D expenditure have a low impact on GDP growth and R\&D expenditure are inefficient in converting GDP.

\section{REFERENCES}

[1] Hong Cancheng. R\&D Expenditure and Economic Growth: An Empirical Study Based on Panel Data of Guangdong Province and Shandong Province [J]. Economic Research Guide, 2015(19): 58-62. (In Chinese)

[2] Chen Xinwei, Yao Zuowen. An Empirical Study on the Relationship between R\&D Expenditure and its Structure and Economic Growth in Anhui Province [J]. Technology Economics, 2011, 30(2): 16-22. (In Chinese)

[3] Xu Shuyi, Tian Baoqin, Zhu Fuqiang. The Impact of R\&D on Productivity in Guangdong Province-An Empirical Study Based on Panel Data of 21 Prefecture-level Cities [J]. Science and Technology Management Research, 2011, 31(6): 71-74. (In Chinese)

[4] Yan Chengliang, Gong Liutang. Measurement of the Contribution of R\&D to China's Economic Growth [J]. Investment Research, 2014(1): 13-23. (In Chinese)

[5] Zhang Jinshui. Analysis of the R\&D Expense Structure of Guangdong Province [J]. Guangdong Science and Technology, 2007(9): 37-38. (In Chinese)

[6] Zhu Mingming. Research on the Relationship between R\&D Expenditure and Economic Growth in Fujian Province $[\mathrm{J}]$. Chinese Market, 2013(26): 112-114. (In Chinese)

[7] Qi Siyun. An Empirical Study on the Role of China's R\&D Activities in Promoting Economic Growth [J]. Economics of the Time, 2012(29): 3030. (In Chinese)

[8] Liu Lu, Guo Bing, Analysis of the Lagging Effect Grey Relation between the Local Government R\&D Expenditure and Economic Growth - Empirical Data from Shanghai 1999 - 2010[J]. Technology and Industry, 2012, 12(10): 81-83. (In Chinese)

[9] Song Wenfei, Wang Jue, Han Xianfeng. Application of Three-stage Data Envelopment Model to Analyze R\&D Efficiency [J]. Science \& Technology Resources of China, 2011, 43(4): 5-11. (In Chinese)

[10] Statistical Yearbook of Guangdong Province: http://www.gdstats.gov.cn/tjsj/gdtjnj/. 